\title{
Early Gastroenteropancreatic Neuroendocrine Tumors: Endoscopic Therapy and Surveillance
}

\author{
Hans Scherübla Guillaume Cadiot ${ }^{\mathrm{b}}$ \\ a Departments of Gastroenterology, Gastrointestinal Oncology and Infectious Diseases, Vivantes Klinikum Am Urban, Berlin, Germany; \\ bervice d'Hépato-Gastroentérologie, Hôpital Robert Debré, Reims, France
}

\section{Keywords}

Neuroendocrine tumor, NET · Carcinoid .

Stomach · Duodenum - Pancreas · Gut - Appendix .

Rectum · Small size · Prognosis - Treatment .

Endoscopy - Endoscopic mucosal resection, EMR .

Endoscopic submucosal dissection, ESD

\section{Summary}

Neuroendocrine neoplasias (NEN) of the stomach, duodenum, pancreas, appendix, or rectum that are $\leq 1 \mathrm{~cm}$ in size as well as well-differentiated with World Health Organization grade 1 (G1) can be considered 'early' neuroendocrine tumors; they have a very good prognosis. Regarding prognosis, neuroendocrine tumors (NET) G1 must be distinguished from well-differentiated NET G2 and poorly differentiated neuroendocrine carcinomas (NEC) G3. NET are increasing, with a rise in the age-adjusted incidence in the USA by about $700 \%$ in the last 40 years. Earlier diagnosis of NET is one of the main epidemiological changes of clinically detected NEN. The general availability of high-resolution endoscopy and advanced radiological imaging techniques has contributed to a shift in the discovery to smallersized $(\leq 10 \mathrm{~mm})$ gastrointestinal and pancreatic NET and earlier tumor stages at diagnosis. Thus, screening colonoscopy is effective in the early diagnosis not only of colorectal adenomas and adenocarcinomas but also of rectal NET. Endoscopic resection is the treatment of choice in NET G1 of the stomach, duodenum (despite gastrinoma), and rectum that are $\leq 10 \mathrm{~mm}$ in size, do not infiltrate the muscularis propria (T1), and do not show angioinvasion (V0, L0). Similarly, histologically proven, early pancreatic NET G1 $(\leq 10 \mathrm{~mm})$ may be managed conservatively by regular surveillance. In con- trast, small $(\leq 1 \mathrm{~cm})$ NET G1 of the jejunum or ileum are not 'early' tumors and have to be resected surgically with lymph node dissection.

(c) 2017 S. Karger GmbH, Freiburg

\section{Introduction}

The classification of the World Health Organization (WHO) stratifies gastrointestinal neuroendocrine neoplasias (NEN) into three groups: neuroendocrine tumors (NET) that are well differentiated and graded according to their proliferative activity into G1 or G2, and neuroendocrine carcinomas (NEC) that are poorly differentiated and graded as NEC G3. The latter are further divided into small cell and large cell neoplasms. Some well-differentiated pancreatic NET (pNET) show a discordantly high proliferative activity of $>20 \%$ and are classified as pNET G3 in the recent WHO classification of malignant tumors [1].

Gastrointestinal NET are on the rise [2]. In the USA, the prevalence and the incidence of gastroenteropancreatic NET/carcinoids was calculated to be $35 / 100,000$ and $5 / 100,000$, respectively [3], revealing a sevenfold increase in the last 40 years. Similar changes have been reported for England [4], Norway [5], and Germany [6]. The most obvious reasons for this phenomenon are a better awareness of and improved diagnostic facilities for NEN as well as an increased and more widespread use of gastrointestinal, high-resolution endoscopy and advanced radiological imaging [4, 5, 7-11]. The overall 5-year survival rate for patients with gastrointestinal NET/carcinoids has improved by more than $20 \%$ in the last 40 years [12-14]. This achievement is due to both early detection and better therapeutic strategies of NET. Today, gastrointestinal NET/ carcinoids are often diagnosed at an early asymptomatic stage [3],

\section{KARGER}

(c) 2017 S. Karger GmbH, Freiburg
Prof. Dr. med. Hans Scherübl

Klinik für Innere Medizin - Gastroenterologie, Gastrointestinale Onkologie und Infektiologie Vivantes-Klinikum Am Urban, Akademisches Lehrkrankenhaus der Charité

Dieffenbachstraße 1, 10967 Berlin, Germany

hans.scheruebl@vivantes.de 
Table 1. Clinicopathological characteristics and prognosis of neuroendocrine neoplasias of the stomach $[9,12,16,18,19]$

\begin{tabular}{|c|c|c|c|c|}
\hline & \multicolumn{3}{|c|}{ Gastric NET G1 (carcinoids) and NET G2 } & \multirow{2}{*}{$\begin{array}{l}\text { Poorly differentiated } \\
\text { - NE gastric cancer (type } 4 \text { ) } \\
\text { gastric NEC G3 }\end{array}$} \\
\hline & type 1 & type 2 & type 3 & \\
\hline Relative frequency, \% & $70-80$ & $5-6$ & $14-25$ & $6-8$ \\
\hline Features & $\begin{array}{l}\text { mostly small }(\leq 1 \mathrm{~cm}) \\
\text { and multiple }\end{array}$ & $\begin{array}{l}\text { mostly small }(\leq 1 \mathrm{~cm}) \\
\text { and multiple }\end{array}$ & often $>2 \mathrm{~cm}$, solitary & mostly $>2 \mathrm{~cm}$, solitary \\
\hline Associated conditions & CAG & MEN1/ZES & no & no \\
\hline Histology & $\begin{array}{l}\text { well-differentiated } \\
\text { G1/G2 }\end{array}$ & $\begin{array}{l}\text { well-differentiated } \\
\text { G1/G2 }\end{array}$ & $\begin{array}{l}\text { well/moderately } \\
\text { differentiated } \mathrm{G} 1 / \mathrm{G} 2^{\mathrm{b}}\end{array}$ & G3 \\
\hline Serum gastrin & (very) high & (very) high & normal & (mostly) normal \\
\hline Gastric pH & anacidic & hyperacidic & normal & (mostly) normal \\
\hline Metastases, \% & $<10$ & $10-30$ & $30-80$ & $80-100$ \\
\hline Tumor-related deaths, $\%$ & no & $<10$ & $25-30$ & $>50$ \\
\hline
\end{tabular}

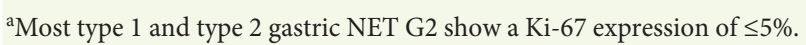

bSome type 3 gastric NET, though well-differentiated, show a Ki-67 index of $>20 \%$ (NET G3).

$\mathrm{CAG}=$ Chronic atrophic gastritis; MEN1 = multiple endocrine neoplasia type $1 ; \mathrm{ZES}=$ Zollinger-Ellison syndrome; MEN1/ZES = ZES associated with MEN1; G1 and G2 = well-differentiated; G3 = poorly differentiated (Ki-67 index of 0-2\%: G1; Ki-67 index of 3-20\%: G2; Ki-67 index of >20\%: G3); NE = neuroendocrine; NET = neuroendocrine tumor; NEC = neuroendocrine carcinoma.

notably G1 tumors with a size below $10 \mathrm{~mm}$. Retrospective data from large national registries and large hospital series, mainly from Japan, Korea, Europe, and the USA, argue for a conservative management of these 'early' gastroenteropancreatic NET G1/carcinoids of the stomach, duodenum, pancreas, and rectum.

\section{Histological Grading of Neuroendocrine Neoplasms}

The risk of metastatic disease of gastrointestinal NEN correlates with histological differentiation (well or poorly differentiated) of the primary, proliferative activity (G1-G3), tumor size, depth of tumor infiltration, and angioinvasion. The histological grading of gastrointestinal NEN (G1-G3) according to the WHO classification is of major prognostic and therapeutic relevance [1].

\section{Prognosis of Gastric Neuroendocrine Tumors/Carcinoids}

At present, the most common form of gastric NET, i.e. type 1 (table 1), is generally diagnosed at an early stage, with $80-90 \%$ of them being $\leq 1 \mathrm{~cm}$ in diameter [9]. These small, well-differentiated tumors only rarely cause specific symptoms; in most instances, they are incidentally found during a gastroscopy being performed for reasons such as anemia or non-specific abdominal symptoms. Type 2 gastric NET, similar to type 1 (table 1), are usually detected at an early stage, and generally have a good prognosis. For all gastric carcinoids the prognosis has much improved [2, 12, 15-17], with the proportion of advanced tumor stages at diagnosis decreasing from $23.8 \%$ in the 1950 s and 1960 s to $6.5-7.9 \%$ in the 1990 s, suggesting that early diagnosis is contributing to the patients' improved survival. In Japan, the rate of advanced stages at diagnosis is as low as $5.1 \%$ today [15]. The 5 -year survival rate of patients
Table 2. Impact of endoscopic screening on the size of rectal neuroendocrine neoplasms (modified from [10])

\begin{tabular}{lll}
$\begin{array}{l}\text { Size of primary } \\
\text { NET, mm }\end{array}$ & $\begin{array}{l}\text { Without } \\
\text { screening, \% }\end{array}$ & $\begin{array}{l}\text { Endoscopic } \\
\text { screening, \% }\end{array}$ \\
\hline$<10$ & $65-80$ & $93.3-100$ \\
$11-20$ & $10-22$ & $0-6.7$ \\
$>20$ & $10-15$ & 0 \\
\hline
\end{tabular}

Table 3. Main factors predicting metastases in patients with rectal neuroendocrine tumors [30]

\begin{tabular}{llc}
\hline Predictive factor & Odds ratio & $95 \%$ CI \\
\hline Tumor size $>14 \mathrm{~mm}$ & 57.5 & $23.3-1,002.6$ \\
Mitotic index $\geq 2 / 10 \mathrm{HPF}$ & 56.2 & $2.4-1,295.8$ \\
Lymphovascular invasion & 65.1 & $1.1-3,846.7$ \\
Muscularis propria invasion & 37.9 & $5.0-290$ \\
\hline
\end{tabular}

$\mathrm{HPF}=$ High-power field; CI = confidence interval.

with gastric NEN has improved from $51 \%$ in the 1970s and 1980 s to $63 \%$ in the 1990 s $[2,15-17]$. According to an analysis of the SEER data by Landry et al. [16], the 5 -year survival is about $71 \%$. Small $(\leq 1 \mathrm{~cm})$, well-differentiated NET G1/carcinoids of the stomach without either infiltration of the muscularis propria or angioinvasion have been shown to have a very low risk of distant metastatic spread $[18,19]$ or carcinoid-related death; they are considered early NET G1 (carcinoids) of the stomach. The 5-year survival of type 1 gastric carcinoids approaches $98 \%$.

\section{Prognosis of Neuroendocrine Tumors/Carcinoids of the Small Bowel}

In the small bowel, NET/carcinoids are most frequently found in the ileum $(>70 \%)$, especially the distal ileum, but recent data 
show that duodenal NET are more common (22\%) nowadays than previously noted [20]. Regarding prognosis, the 5-year survival rate has risen from $51.9 \%$ in the 1970 s and 1980 s to $60.5 \%$ in the 1990 s [12]. In an analysis of the years 1999-2004, Strosberg et al. [13] reported a 5 -year survival rate of about $75 \%$ in patients with metastatic NET/carcinoid disease of the small intestine receiving multimodal therapy. The earlier detection of intestinal NET may have led to improved prognosis $[11,14]$, since the proportion of advanced disease of small intestine NET (at the time of diagnosis) has decreased from $31.3 \%$ in the 1970 s and 1980 s to $22.4 \%$ in the 1990 s and finally to $<18.9 \%$ between 2002 and 2004 [3, 12, 15, 20]. With duodenal NET/carcinoids, distant metastases are nowadays observed in less than $6-10 \%$ of cases $[15,21-23]$. If duodenal NET/ carcinoids are $\leq 10 \mathrm{~mm}$ in size, are type G1, show neither angioinvasion nor infiltration of the muscularis propria, and have no associated hormonal syndrome, they have a very low risk of metastasis and can be considered 'early' duodenal NET/ carcinoids. In contrast, duodenal gastrinomas (i.e. duodenal NET associated with the Zollinger-Ellison syndrome (ZES), with or without multiple endocrine neoplasia 1 (MEN1)) as well as jejunal or ileal NET/carcinoids of only a few millimeters in size may already have spread to locoregional lymph nodes and distant organs. Thus, the term 'early' tumor is appropriate neither for jejunal and ileal NET/carcinoids nor for duodenal gastrinomas and should not be used.

\section{Prognosis of Rectal Neuroendocrine Tumors/Carcinoids}

Thanks to the introduction of national colorectal cancer screening in several countries, the vast majority (85-95\%) of rectal NET/ carcinoids is detected at an early stage (table 2). This shift to earlier stages has improved the patients' 5 -year survival rate by more than $20 \%$ [10]. The 5 -year survival rate of patients with distant metastases of rectal NET/carcinoids ranges from 15 to $30 \%$ [22, 24, 25]. For node-positive rectal carcinoid disease (without distant metastases) the 5-year survival rate is $54-73 \%$ [24, 25-27]. In contrast, histologically, node-negative rectal NET/carcinoids that are $\leq 1 \mathrm{~cm}$ in size and do not show angioinvasion or infiltration of the muscular layer have an excellent 5-year survival rate of 98.9-100\% [2, 22, $24,25]$. Such rectal NET G1/carcinoids $\leq 1 \mathrm{~cm}$ may be regarded as 'early' NET. Guidelines published by the North American Neuroendocrine Tumor Society (NANETS) do not recommend followup of patients with well-differentiated rectal NET G1/carcinoids $\leq 1 \mathrm{~cm}$ in size that have been completely resected and that had not invaded the muscularis propria [28]. Yet the European Neuroendocrine Tumor Society (ENETS) recommends further surveillance of these patients in case of angioinvasion, invasion of the muscular layer (T2), or G2 grading [29]. A recent literature analysis showed that independent factors for the development of metastases were tumor size $>14 \mathrm{~mm}$, mitotic index $\geq 2 / 10$ high-power field, lymphovascular invasion, and invasion of the muscularis propria (table 3) [30]. There are very few data on the Ki-67 proliferation index in rectal NET, and most data rely on the mitotic index.

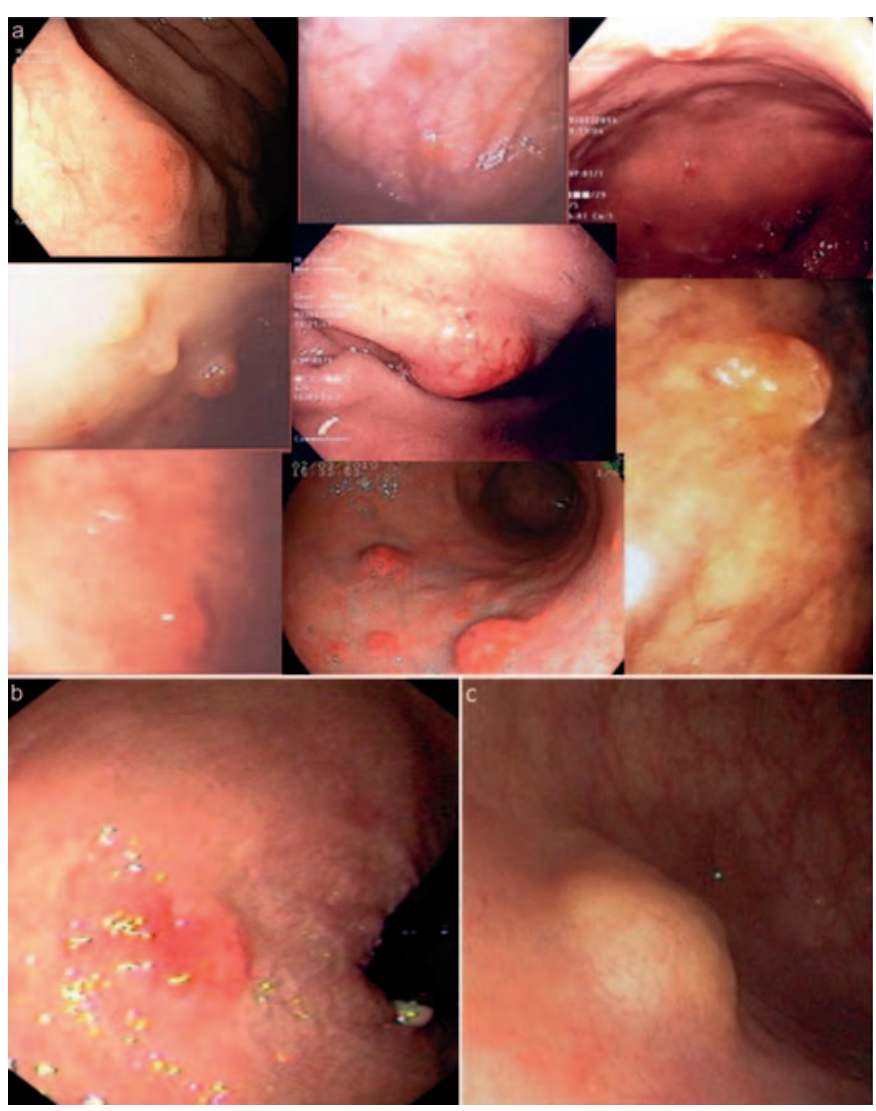

Fig. 1. Endoscopic images of early gastrointestinal neuroendocrine tumors (NET) G1/carcinoids. a Multiple, small $(<1 \mathrm{~cm})$, type 1 gastric NET G1/carcinoids associated with autoimmune chronic atrophic gastritis and pernicious anemia; b NET G1/carcinoid of the rectum measuring $7 \mathrm{~mm}$; c NET G1/carcinoid of the rectum measuring $10 \mathrm{~mm}$ (modified from [10]).

\section{Prognosis of Appendiceal Neuroendocrine Tumors G1 VO LO RO}

Appendiceal NEN are usually NET G1/carcinoids that are incidentally found in patients undergoing appendectomy for suspected acute appendicitis. The term 'early appendiceal NET/carcinoid' may be considered for tumors that are G1, measure $\leq 10 \mathrm{~mm}$, show no angioinvasion, are confined both to the tip of the appendix and to the wall (without invasion of the mesoappendix), and have been completely (R0) removed by appendectomy. Such early appendiceal carcinoids have a very low risk of distant metastatic spread. Neither ENETS nor NANETS recommend further surveillance of patients with these early appendiceal NET that have been R0-resected $[31,32]$.

\section{Prognosis of Sporadic Pancreatic Neuroendocrine Tumors G1}

An international European study group evaluated the clinicopathological characteristics of 926 NEN of the pancreas and correlated clinical outcome with tumor size and histological grading [33]. 
Table 4. Therapy of gastric neuroendocrine neoplasias (types 1-4)

\begin{tabular}{llll}
\hline & NET G1 without risk factors (for metastatic disease) & Risk factors $^{\mathrm{a}}$ \\
\hline Size & $\leq 1 \mathrm{~cm}$ & $1-2 \mathrm{~cm}$ & mostly $>2 \mathrm{~cm}$ \\
Type 1 & EMR $^{\mathrm{b}}$ & EMR/ESD & surgery \\
Type 2 & EMR $^{\mathrm{b}}$ & EMR/ESD & surgery \\
Type 3 & EMR/ESD or surgery & surgery & surgery \\
Type 4 & & & surgery \\
\hline
\end{tabular}

aRisk factors for metastatic disease are angioinvasion, G2-G3 histological grading, infiltration of the muscularis propria, enlarged regional lymph nodes, or tumor size $\geq 2 \mathrm{~cm}$.

${ }^{b}$ EMR may be considered for gastric NET G2 $\leq 1 \mathrm{~cm}$, when Ki-67 is $\leq 5 \%$.

Patients managed by EMR/ESD should be surveilled every 12 months. Type 4 gastric NEN are never benign; they are neuroendocrine carcinomas (NEC).

$\mathrm{EMR}=$ Endoscopic mucosal resection; $\mathrm{ESD}=$ endoscopic submucosal dissection; NET = neuroendocrine tumors.
In this large retrospective analysis, no tumor-related deaths were observed in patients with well-differentiated $\mathrm{pNET}<2 \mathrm{~cm}$ in diameter. Similarly, a study from the USA compared the survival of patients suffering from non-functioning, asymptomatic pNET $<4 \mathrm{~cm}$ that were either surgically resected or managed conservatively [34]. No difference in survival was reported. Neither distant metastases nor tumor-related deaths were observed in the conservatively managed patients with asymptomatic pNET of a mean size of $\leq 1 \mathrm{~cm}$ [34].

Therefore, non-MEN1-related, non-functioning and asymptomatic NET G1 $\leq 1 \mathrm{~cm}$ of the pancreas can be considered as sporadic, early pNET. Such early $(\leq 1 \mathrm{~cm})$, histologically proven pNET G1 have a very low risk of distant metastatic spread and in particular of NET-related death. The probability of NET-related death in patients with sporadic, non-functioning, early $(\leq 1 \mathrm{~cm})$ pNET G1 is certainly lower than the current mean nationwide in-hospital mortality following pancreatic surgery [35].

The main issue when considering conservative management is to be certain of G1 grade. Biopsies are often obtained via fine needle aspiration guided by endoscopic ultrasound. Is has been shown in a series of pNET patients managed by pancreatic surgery that preoperative cytological assessment using fine needle aspiration underestimated the tumor grade, especially in cystic lesions [36]. Thus, Tru-cut biopsies (19-gauge) are recommended for reliable histological grading of pNET.

\section{Diagnosis of Early Neuroendocrine Tumors G1 of the Stomach, Duodenum or Rectum}

Both endoscopic screening and the increasingly widespread availability of gastrointestinal endoscopy have led to a shift in the discovery to smaller-sized $(\leq 10 \mathrm{~mm})$ gastrointestinal NET G1/carcinoids. Most of these early tumors are asymptomatic, but occasionally they present with abdominal discomfort, gastrointestinal bleeding, or altered bowel habits. If they come along with a hormonal hypersecretion syndrome, i.e. with ZES in duodenal gastrinoma, they are called functional NET. Functional NET may already have spread to the regional lymph nodes or the liver despite a small size of $\leq 1 \mathrm{~cm}$. Functional intestinal NET are not to be considered 'early' tumors and will not be discussed here in detail. Endoscopy is the method of choice to detect (asymptomatic) gastric, duodenal or rectal NET G1/carcinoids even at an early stage (fig. 1).

\section{Therapy of Early Gastroenteropancreatic Neuroendocrine Tumors/Carcinoids}

Endoscopic Techniques Used for the Resection of Superficial Digestive Tumors

Conventional polypectomy with a snare for flat mucosal lesions, especially NET/carcinoids, should be avoided because complete resection is often not achieved, e.g. 59\% in a recent review of rectal NET [30]. Instead, endoscopic mucosal resection (EMR) or endoscopic submucosal dissection (ESD) should be preferred. In EMR, snare resection is preceded by the submucosal injection of saline in order to raise the tumor and cut into the submucosa below the tumor (fig. 2). EMR can be performed with or without a cap or a ligation device [37]. ESD is preferred to EMR in case of suspicion of limited submucosal invasion or a tumor larger than $2 \mathrm{~cm}$ [38]. After submucosal injection of saline, the submucosa is dissected with specific knives in order to achieve endoscopic en bloc resection of the whole neoplasm. ESD requires specific training and is usually performed in expert endoscopic centers. Considering rectal NET/carcinoids, both EMR with a cap/ligation device and ESD allow complete resection in about 90\% [30]. The rate of perforation is higher with ESD but perforations are usually closed during the endoscopic procedure.

\section{Indications for NET/Carcinoids}

Small $(\leq 1 \mathrm{~cm})$, well-differentiated NET G1/carcinoids of the stomach, duodenum, or rectum that neither infiltrate the muscularis propria nor show angioinvasion have a very low risk of metastatic spread; i.e., they are considered as early NET/carcinoids. The treatment of choice of early NET/carcinoids of the stomach, duodenum, or rectum is endoscopic resection (table 4-6). Endoscopic ultrasound is excellent for determining the exact tumor size and for excluding infiltration of the NET/carcinoids into the muscularis propria (T2) or enlarged regional lymph nodes. 
Table 5. Therapy of duodenal neuroendocrine tumors (without multiple endocrine neoplasia type 1)

\begin{tabular}{|c|c|c|c|}
\hline \multirow[b]{2}{*}{ Size } & \multicolumn{2}{|c|}{$\begin{array}{l}\text { NET G1 without risk factors } \\
\text { (for metastatic disease) }\end{array}$} & \multirow{2}{*}{$\begin{array}{l}\text { Risk factors }^{\mathrm{a}} \\
\text { mostly } \geq 2 \mathrm{~cm}\end{array}$} \\
\hline & $\leq 1 \mathrm{~cm}$ & $1-2 \mathrm{~cm}$ & \\
\hline Sporadic NET & $\mathrm{EMR}^{\mathrm{b}, \mathrm{c}}$ & EMR $^{c}$ or surgery ${ }^{d}$ & surgery ${ }^{d}$ \\
\hline $\begin{array}{l}\text { Sporadic gastrinoma } \\
\text { (localized) }\end{array}$ & surgery ${ }^{d}$ & surgery ${ }^{d}$ & surgery $^{d}$ \\
\hline
\end{tabular}

aRisk factors for metastatic disease are angioinvasion, G2-G3 histological grading, infiltration of the muscularis propria, enlarged regional lymph nodes, or tumor size $\geq 2 \mathrm{~cm}$.

bIn the elderly, asymptomatic duodenal NET G1 $\leq 1 \mathrm{~cm}$ may just be followed up [44].

'EMR may be considered for NET G2 $\leq 1 \mathrm{~cm}$, when Ki-67 is $\leq 5 \%$. Endoscopic submucosal dissection (ESD) increases the risk of duodenal perforation (most often managed endoscopically) but increases complete resection rate. ESD may be considered in some patients if managed in reference centers. ${ }^{\mathrm{d}}$ With lymph node dissection.

EMR = Endoscopic mucosal resection; NET = neuroendocrine tumors. a

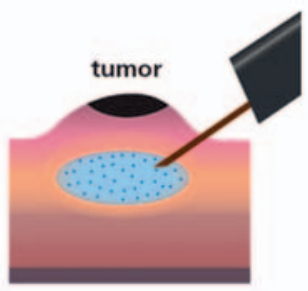

b
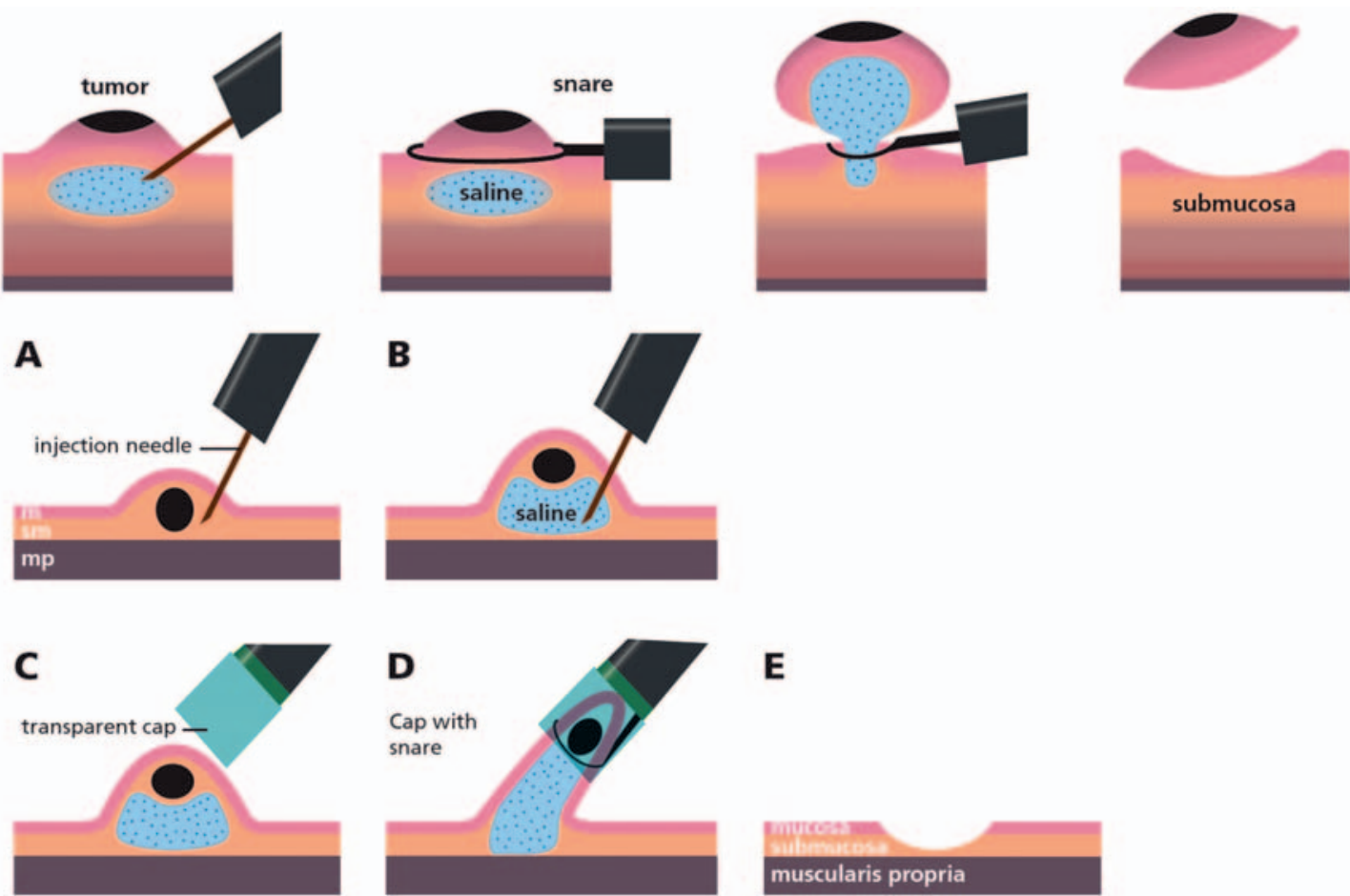

Fig. 2. Endoscopic mucosal resection (EMR) und endoscopic submucosal dissection (ESD). EMR can be performed a without or b with a cap. $\mathbf{c}$ ESD.

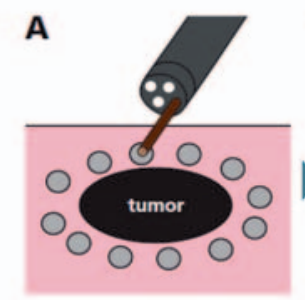

1. Make markings around the tumos:

D

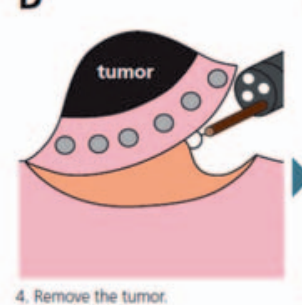

4. Remove the tumot:

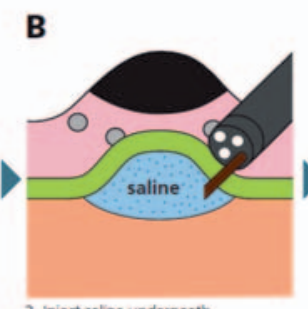

2. inject saline underneath the lesion to lift it.

E
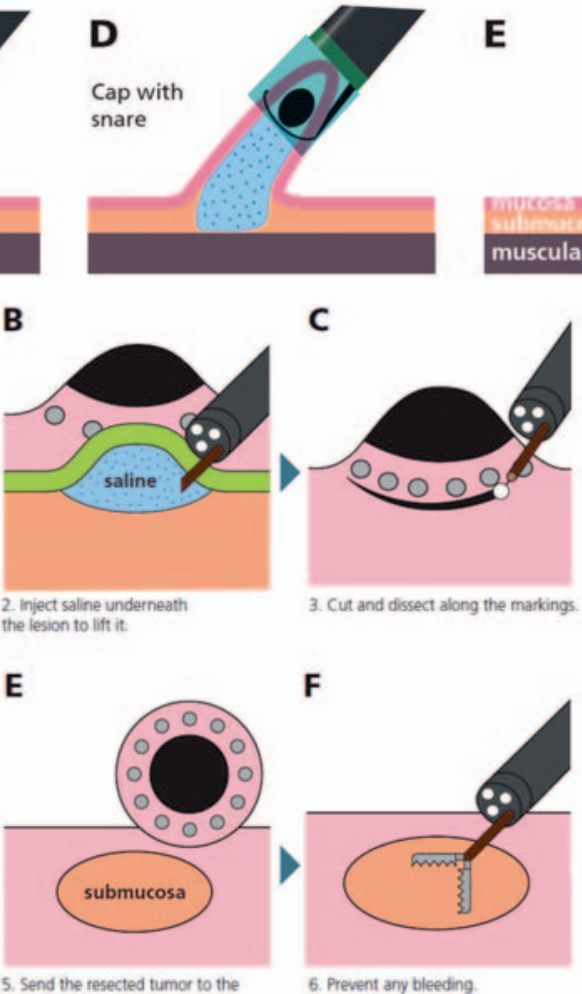
5. Send the resected tumor to the
pathologist.

6. Prevent any bleeding.
C

$\mathbf{F}$

E

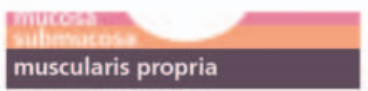

muscularis propria

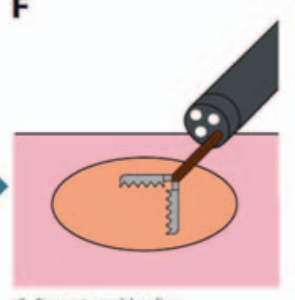

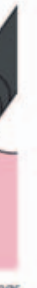

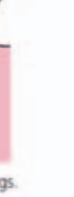


Table 6. Therapy of rectal neuroendocrine tumors G1

\begin{tabular}{llll}
\hline & NET G1 without risk factors (for metastatic disease) & Risk factors $^{\mathrm{a}}$ \\
\hline Size & $\leq 1 \mathrm{~cm}$ & $1-2 \mathrm{~cm}$ & mostly $>2 \mathrm{~cm}$ \\
\hline G1 & EMR/ESD & $\begin{array}{l}\text { EMR/ESD for NET }<15 \mathrm{~mm} ; \\
\text { surgery }\end{array}$ & surgery \\
\hline
\end{tabular}

${ }^{\text {a}}$ Risk factors for metastatic disease are angioinvasion, G2-G3 histological grading, infiltration of the muscularis propria, enlarged regional lymph nodes, or tumor size $\geq 2 \mathrm{~cm}$.

bEMR/ESD may be considered for NET G2 $\leq 1 \mathrm{~cm}$, when Ki- 67 is $\leq 5 \%$ and final therapy will be discussed after pathological analysis of the resected specimen.

$\mathrm{EMR}=$ Endoscopic mucosal resection; $\mathrm{ESD}=$ endoscopic submucosal dissec tion; NET $=$ neuroendocrine tumors.

Early NET/carcinoids of the stomach, duodenum, or rectum are generally removed by EMR $[30,39,40]$. In early rectal NET/carcinoids and in particular in rectal NET G1 of 9-14 mm in size, ESD can be considered [41]. ESD of duodenal NET increases the complete resection rate to almost $100 \%$ when compared to EMR (about $50 \%)$, but at the expense of a higher perforation rate [42]. Endoscopic therapy of duodenal NET comes with some interventional morbidity and can cause mortality particularly in multimorbid elderly patients [42]. The recent German S2k guideline does not recommend ESD for early duodenal NET. In any case, the resected specimen has to be carefully evaluated regarding grade, angioinvasion, and infiltration of the deep resection margin. In case of angioinvasion, histological infiltration of the muscularis propria (T2), or grade G2/G3, surgery with lymph node dissection is the therapy of choice in localized NET disease. However, in some cases of small $(\leq 1 \mathrm{~cm})$ type 3 gastric NET G1/G2 (Ki-67 $<5 \%)$ totally resected (R0) by endoscopy and in the absence of the other risk factors for metastatic disease, endoscopic resection might be sufficient [43].

Early $(\leq 1 \mathrm{~cm})$ appendiceal NET G1 are adequately managed by appendectomy. R0-resected, early $(\leq 1 \mathrm{~cm})$ NET G1 of the appendix do not require follow-up.
Sporadic, non-functioning and asymptomatic NET G1 $\leq 1 \mathrm{~cm}$ of the pancreas are found incidentally nowadays. Due to their excellent prognosis, histologically proven early pNET can be managed conservatively and should be surveilled by endoscopic ultrasound or magnetic resonance imaging every 12 months. In case of obvious tumor growth, the patient should be advised for surgery.

It is important to note that small $(\leq 1 \mathrm{~cm})$ NET G1 of the jejunum or ileum are by no means 'early' tumors and have to be resected surgically with systematic lymph node dissection. The risk of regional lymph node metastasis is high even in small $(\leq 1 \mathrm{~cm})$ NET G1 of the jejunum or ileum.

\section{Conclusion}

High-resolution endoscopy and advanced radiological imaging techniques can detect gastroenteropancreatic NET G1/carcinoids even when very small. The general widespread use and availability of gastrointestinal endoscopy has led to a shift in the discovery towards smaller-sized ( $\leq 10 \mathrm{~mm}$ ) gastrointestinal NET/carcinoids. In the last 40 years, the 5 -year survival rate of patients with gastroenteropancreatic NET/carcinoids disease has increased by more than $20 \%$. Most patients with early $(\leq 1 \mathrm{~cm})$, well-differentiated NET G1/carcinoids of the stomach, duodenum, rectum, or pancreas can be managed conservatively and be followed up by endoscopic surveillance. It should be noted that patients with (previous) NET/carcinoid disease have a 15-25\% risk for second malignancies including breast (in women), prostate (in men), colorectal, and gastric cancer.

\section{Disclosure Statement}

The authors do not have any conflict of interests concerning this review paper.

\section{References}

1 Brierley J, Gospodarowicz M, Wittekind C (eds): TNM Classification of Malignant Tumours, ed 8. Hoboken, NJ; Wiley-Blackwell, 2016.

2 Modlin IM, Oberg K, Chung DC, Jensen RT, de Herder WW, Thakker RV, Caplin M, Delle Fave G, Kaltsas GA, Krenning EP, Moss SF, Nilsson O, Rindi G, Salazar R, Ruszniewski P, Sundin A: Gastroenteropancreatic neuroendocrine tumours. Lancet Oncol 2008;9:61-72.

3 Yao JC, Hassan M, Phan A, Dagohoy C, Leary C, Mares JE, Abdalla EK, Fleming JB, Vauthey JN, Rashid A, Evans DB: One hundred years after 'carcinoid': epidemiology of and prognostic factors for neuroendocrine tumors in 35,825 cases in the United States. J Clin Oncol 2008;26:3063-3072.
4 Ellis L, Shale MJ, Coleman MP: Carcinoid tumors of the gastrointestinal tract: trends in incidence in England since 1971. Am J Gastroenterol 2010;105:25632569.

5 Hauso O, Gustafsson BI, Kidd M, Waldum HL, Drozdov I, Chan AK, Modlin IM: Neuroendocrine tumor epidemiology: contrasting Norway and North America. Cancer 2008;113:2655-2664.

6 Scherübl H, Streller B, Stabenow R, Herbst H, Höpfner M, Schwertner C, Steinberg J, Eick J, Ring W, Tiwari $\mathrm{K}$, Zappe S: Clinically detected gastroenteropancreatic neuroendocrine tumors are on the rise: epidemiological changes in Germany. World J Gastroenterol 2013; 19:9012-9019.
7 Kaminski M, Polkowski M, Regula J: Prevalence and endoscopic features of rectal neuroendocrine tumors (carcinoids) among 50,148 participants of the Polish colorectal-cancer screening programme. Gut 2007; 56(suppl III):A310.

8 Hosokawa O, Miyanaga T, Kaizaki Y, Hattori M, Dohden K, Ohta K, Itou Y, Aoyagi H: Decreased death from gastric cancer by endoscopic screening: association with a population-based cancer registry. Scand J Gastroenterol 2008;43:1112-1115.

9 Scherübl H, Cadiot G, Jensen RT, Rösch T, Stölzel U, Klöppel G: Neuroendocrine tumors of the stomach (gastric carcinoids) are on the rise: small tumors, small problems? Endoscopy 2010;42:664-671. 
10 Scherübl H: Rectal carcinoids are on the rise: early detection by screening endoscopy. Endoscopy 2009;41: 162-165.

11 Scherübl H, Jensen RT, Cadiot G, Stölzel U, Klöppel G: Neuroendocrine tumors of the small bowels are on the rise: early aspects and management. World J Gastrointest Endosc 2010;2:325-334.

12 Modlin IM, Lye KD, Kidd M: A 5-decade analysis of 13,715 carcinoid tumors. Cancer 2003;97:934-959.

13 Strosberg J, Gardner N, Kvols L: Survival and prognostic factor analysis of 146 metastatic neuroendocrine tumors of the midgut. Neuroendocrinology 2009;89: 471-476.

14 Zar N, Garmo H, Holmberg L, Rastad J, Hellman P: Long-term survival of patients with small intestinal carcinoid tumors. World J Surg 2004;28:1163-1168.

15 Ito T, Tanaka M, Sasano H, Osamura YR, Sasaki I, Kimura W, Takano K, Obara T, Ishibashi M, Nakao K, Doi R, Shimatsu A, Nishida T, Komoto I, Hirata Y, Imamura M, Kawabe K, Nakamura K: Preliminary results of a Japanese nationwide survey of neuroendocrine gastrointestinal tumors. J Gastroenterol 2007;42: 497-500.

16 Landry CS, Brock G, Scoggins CR, McMasters KM, Martin RC: A proposed staging system for gastric carcinoid tumors based on an analysis of 1,543 patients. Ann Surg Oncol 2009; 16:51-60.

17 Modlin IM, Lye KD, Kidd M: A 50-year analysis of 562 gastric carcinoids: small tumor or larger problem? Am J Gastroenterol 2004;99:23-32.

18 Klöppel G, Clemens A: The biological relevance of gastric neuroendocrine tumors. Yale J Biol Med 1996;69: 69-74.

19 Ruszniewski P, Delle Fave G, Cadiot G, Komminoth P, Chung D, Kos-Kudla B, Kianmanesh R, Hochhauser D, Arnold R, Ahlman H, Pauwels S, Kwekkeboom DJ, Rindi G: Well-differentiated gastric tumors/carcinomas. Neuroendocrinology 2006;84:158-164.

20 Bilimoria KY, Bentrem DJ, Wayne JD, Ko CY, Bennett CL, Talamonti MS: Small bowel cancer in the United States: changes in epidemiology, treatment, and survival over the last 20 years. Ann Surg 2009;249:63-71.

21 Soga J: Endocrinocarcinomas (carcinoids and their variants) of the duodenum. An evaluation of 927 cases. J Exp Clin Cancer Res 2003;22:349-363.

22 Soga J: Early-stage carcinoids of the gastrointestinal tract: an analysis of 1914 reported cases. Cancer 2005; 103:1587-1595.

23 Garbrecht N, Anlauf M, Schmitt A, et al: Somatostatinproducing neuroendocrine tumors of the duodenum and pancreas: incidence, types, biological behavior, association with inherited syndromes, and functional activity. Endocr Relat Cancer 2008;15:229-241.
24 Modlin I, Drozdov I, Gustafsson B, Öberg K, Kidd M: Rectal neuroendocrine tumors - diagnosis and treatment; in Modlin I, Öberg K (eds): A Century of Advances in Neuroendocrine Tumor Biology and Treatment. Felsenstein, CCCP, 2007, pp 124-133.

25 Konishi T, Watanabe T, Kishimoto J, Kotake K, Muto T, Nagawa H: Prognosis and risk factors of metastasis in colorectal carcinoids: results of a nationwide registry over 15 years. Gut 2007;56:863-868.

26 Konishi T, Watanabe T, Muto T, Kotake K, Nagawa H: Risk factors for lymph node and distant metastasis in colorectal carcinoids: an analysis of nationwide registry in Japan over 15 years. J Clin Oncol 2006;24:3620.

27 Konishi T, Watanabe T, Nagawa H, Oya M, Ueno M, Kuroyanagi H, Fujimoto Y, Akiyoshi T, Yamaguchi T, Muto T: Treatment of colorectal carcinoids: a new paradigm. World J Gastrointest Surg 2010;2:153-156.

28 Anthony LB, Strosberg JR, Klimstra DS, Maples WJ, O'Dorisio TM, Warner RR, Wiseman GA, Benson AB, Pommier RF: The NANETS consensus guidelines for the diagnosis and management of gastrointestinal neuroendocrine tumors (NETs): well-differentiated NETs of the distal colon and rectum. Pancreas 2010;39:767-774.

29 Ramage JK, Goretzki PE, Manfredi R, Komminoth P, Ferone D, Hyrdel R, Kaltsas G, Kelestimur F, Kvols L, Scoazec JY, Garcia MI, Caplin ME: Consensus guidelines for the management of patients with digestive neuroendocrine tumours: well-differentiated colon and rectum tumour/carcinoma. Neuroendocrinology 2008;87:31-39.

30 de Mestier L, Brixi H, Gincul R, et al: Updating the management of patients with rectal neuroendocrine tumors. Endoscopy 2013;45:1039-1046.

31 Plöckinger U, Couvelard A, Falconi M, Sundin A, Salazar R, Christ E, de Herder WW, Gross D, Knapp WH, Knigge UP, Kulke MH, Pape UF: Consensus guidelines for the management of patients with digestive neuroendocrine tumours: well-differentiated tumour/carcinoma of the appendix and goblet cell carcinoma. Neuroendocrinology 2008;87:20-30.

32 Boudreaux JP, Klimstra DS, Hassan MM, Woltering EA, Jensen RT, Goldsmith SJ, Nutting C, Bushnell DL, Caplin ME, Yao JC: The NANETS consensus guideline for the diagnosis and management of neuroendocrine tumors: well-differentiated neuroendocrine tumors of the jejunum, ileum, appendix, and cecum. Pancreas 2010;39:753-766.

33 Rindi G, Falconi M, Klersy C, et al: TNM staging of neoplasms of the endocrine pancreas: results from a large international cohort study. J Natl Cancer Inst 2012;104:764-777.
34 Lee L, Grant C, Salomao D, et al: Small, non-functioning, asymptomatic pancreatic neuroendocrine (PNETs): role of nonoperative management. Surgery 2012;152:965-974.

35 Nimptsch U, Krautz C, Weber G, Mansky T, Grützmann R: Nationwide in-hospital mortality following pancreatic surgery in Germany is higher than anticipated. Ann Surgery 2016;264:1082-1090.

36 Rebours V, Cordova J, Couvelard A, Fabre M, Palazzo L, Vullierme MP, Hentic O, Sauvanet A, Aubert A, Bedossa P, Ruszniewski P: Can pancreatic neuroendocrine tumour biopsy accurately determine pathological characteristics? Dig Liver Dis 2015;47:973-977.

37 ASGE Technology Committee; Hwang JH, Konda V, Abu Dayyeh BK, Chauhan SS, Enestvedt BK, Fujii-Lau LL, Komanduri S, Maple JT, Murad FM, Pannala R, Thosani NC, Banerjee S: Endoscopic mucosal resection. Gastrointest Endosc 2015;82:215-226.

38 Pimentel-Nunes P, Dinis-Ribeiro M, Ponchon T, et al Endoscopic submucosal dissection: European Society of Gastrointestinal Endoscopy (ESGE) Guideline. Endoscopy 2015;47:829-854

39 Scherübl H, Jensen RT, Cadiot G, Stölzel U, Klöppel G: Management of early gastrointestinal neuroendocrine neoplasms. World J Gastrointest Endosc 2011;16:133139.

40 Kim GH, Kim JI, Jeon SW, Moon JS, Chung IK, Jee SR Kim HU, Seo GS, Baik GH: Endoscopic resection for duodenal carcinoid tumors: a multicenter, retrospective study. J Gastroenterol Hepatology 2014;29:318324.

41 Yang DH, Park Y, Park SH, Kim KJ, Ye BD, Byeon JS, Myung SJ, Yang SK: Cap-assisted endoscopic mucosal resection for rectal neuroendocrine tumors: comparisons with conventional endoscopic mucosal resection and endoscopic submucosal dissection (with videos). Gastrointest Endosc 2016;83:1015-1022.

42 Gincul R, Ponchon T, Napoleon B, Scoazec JY, Guillaud O, Saurin JC, Ciocirlan M, Lepilliez V, Pioche M, Lefort C, Adham M, Pialat J, Chayvialle JA, Walter T: Endoscopic treatment of sporadic small duodenal and ampullary neuroendocrine tumors. Endoscopy 2016; 48:979-986.

43 Kwon YH, Jeon SW, Kim GH, Kim JI, Chung IK, Jee SR, Kim HU, Seo GS, Baik GH, Choi KD, Moon JS Long-term follow up of endoscopic resection for type 3 gastric NET. World J Gastroenterol 2013;19:87038708.

44 Min BH, Kim ER, Lee JH, Kim KM, Min YW, Rhee PL, Kim JJ, Rhee JC: Management strategy for small duodenal carcinoid tumors: does conservative management with close follow-up represent an alternative to endoscopic treatment? Digestion 2013;87:247-253. 